\title{
In Situ Observation of the Role of Alumina Particles on the Crystallization Behavior of Slags
}

\author{
C. ORRLING, S. SRIDHAR and A. W. CRAMB \\ Center for Iron and Steelmaking Research, Carnegie Mellon University, Pittsburgh, PA 15213 USA.
}

(Received on March 3, 2000; accepted in final form on May 11, 2000)

\begin{abstract}
The confocal laser scanning microscope (CLSM) allows crystallization behavior in liquid slags to be observed in situ at high temperatures. Slags in the lime-silica-alumina-magnesia system are easily under cooled and it is possible to construct time temperature transformation (TTT) diagrams for this system. The presence of solid alumina particles in these liquid slags was studied to determine if these particles act as heterogeneous nucleation sites that cause the precipitation of solid material within slags. The introduction of alumina particles reduced the incubation time for the onset of crystallization and increased the temperature at which crystallization was observed in the slags to close to the liquidus temperature for the slag. Crystal growth rates are in a good agreement with Ivantsov's solution of the problem of diffusion controlled dendritic growth. Alumina appears to be a potent nucleating agent in the slag systems that were studied.
\end{abstract}

KEY WORDS: slags; continuous casting; solidification; crystallization; alumina; confocal microscopy.

\section{Introduction}

Slags are present in the various stages of the steelmaking process as covers to the molten steel or, in form of inclusions inside the steel. In the case of slag covers the slag has multiple functions to perform such as (i) protecting the molten metal from re-oxidation, (ii) inclusion removal and (iii) heat transfer control and lubrication at the mold/strand gap. The performance of the slag is dependent on the properties of the slag, which are in turn related to the temperature and the ionic and polymeric structural units that constitute the slag. One such property is the crystallization behavior of slags, which influences the performance of various slags in many aspects. For example:

- the effect of temperature and cooling rate on the precipitation of solid material in slags is an important issue in the use of liquid slags since the viscosity and heat transfer in the slag are affected,

- the crystallization of the mold slag layer between the mold wall and the steel strand has a decisive effect on both the lubrication and the heat transfer rate in the mold.

Solid slag inclusions are often modified into liquid inclusions in order to avoid nozzle clogging and to improve the final quality of the steel product. Hard crystallized slag inclusions may, if they are sub surface, cause surface defects on rolled product. Although the practice of modifying solid to liquid inclusions is well known, few studies have been made on the transition of the liquid slag inclusions to solid inclusions as temperature decreases during casting of the steel product. Sridhar and $\mathrm{Cramb}^{1)}$ and Tse et al. ${ }^{2)}$ studied the dissolution of alumina inclusions in slags. They found that at temperatures $70^{\circ} \mathrm{C}$ above the liquidus temperature the formation of a crystalline layer on the alumina particle protected the inclusion from dissolution.

A technique that has been extensively used by $\operatorname{IRSID}^{3,4)}$ for obtaining crystallization data of the $\mathrm{SiO}_{2}-\mathrm{CaO}-\mathrm{Al}_{2} \mathrm{O}_{3}-$ $\mathrm{MgO}$ system consists of melting and holding the slag Sample at an elevated temperature above its melting point, before cooling the Sample to an isothermal temperature where the Sample is held for different holding times. After the specific holding time the Sample is quenched and inspected by optical microscope and/or by Scanning Electron Microscope (SEM). The phase and morphology of the present crystals have been determined. The holding time for which the first crystals can be observed is classified as the onset of crystallization and the results are given in the form of TTT curves. Orrling et al. ${ }^{5,6)}$ have by the means of the Double Hot Thermocouple Technique been able to determine compositional effects for the onset of crystallization in Mold Slags by obtaining TTT and CCT curves for a different slag compositions. The crystal growth of binary glass ceramic materials has been studied by a number of different researchers and the crystal growth mechanisms as function of undercooling have been determined. ${ }^{6-15)}$

In this study the crystallization behavior of synthetic slags (with the addition of alumina particles as innoculants) has been studied in situ by the means of the Confocal Laser Scanning Microscope. The objectives of this paper are to:

- observe in situ the heterogeneous crystallization taking place on fused $\mathrm{Al}_{2} \mathrm{O}_{3}$ particles in synthetic slags and assess the effects of temperature on the crystal morphology and growth rate

- investigate whether theories of crystal growth can be applied to crystallization of multicomponent liquid oxide system, i.e. slags. 


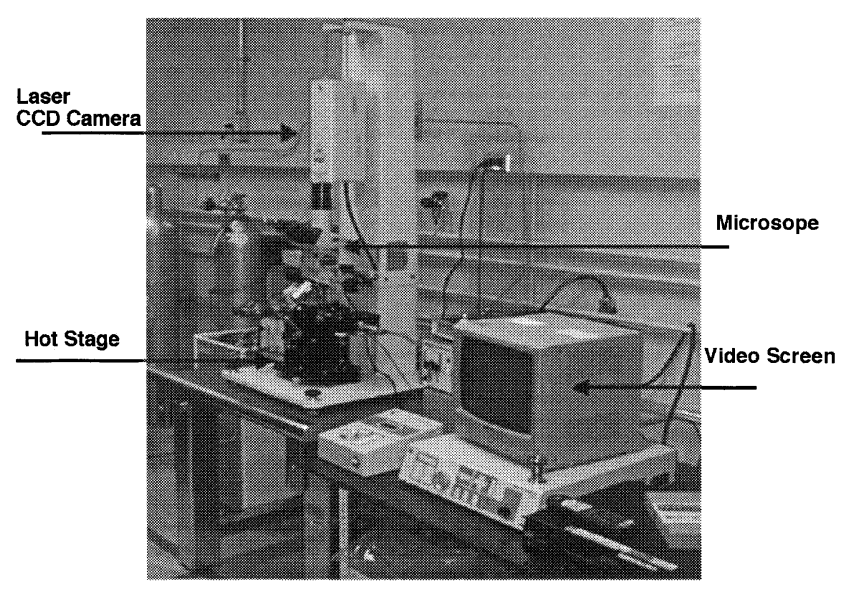

Fig. 1. Picture of confocal scanning laser microscope.

\section{Experimental Technique}

\subsection{Confocal Scanning Laser Microscopy}

Confocal scanning laser microscopy (CSLM) combines the advantages of confocal optics and a He-Ne laser and makes it thereby possible to observe Samples at high resolution at elevated temperatures. The confocal optics enables the (i) detection of a strong signal from the focal plane while (ii) decreasing the intensity of signals not in the focal plane. By scanning a surface at various focal depths, a 3D image is constructed and thus images of uneven Samples can be obtained. The utilization of laser results in high illumination intensity compared to the thermal radiation at elevated temperatures and thus increases the resolution between different phases. The CLSM consists of the equipment listed below. Actual image of the apparatus is shown in Fig. 1:

- Confocal scanning laser microscope

Video signal processing/control unit

Camera head

Monitor

Monitor connection cable

Microscope adapter

Operation manuals

- High temperature heating system

Furnace/chamber system model E1S

Temperature control system

Superimpose (temperature and time)

Standard accessories

The CLSM system has been used extensively for studying the behavior of inclusions on metallic melts ${ }^{16)}$ and solidification and melting behavior. ${ }^{17,18)}$

As many slag systems are transparent in the liquid state the crystallization within the melt can be readily studied in the CLSM. The CLSM is well suited for studying the effect of adding solid particles such as alumina, titania, magnesia and zirconia to the melt as innoculants for crystallization. Solid particles are added to the top of the solid slag and immerse in to the melt during melting. The CLSM is focused on a single particle and the temperature is decreased to the experimental temperature where crystallization occurs. In the present experiments the cooling rate was set to $5^{\circ} \mathrm{C} / \mathrm{s}$. A schematic of the Sample setup of the CLSM experiments can be seen in Fig. 2.

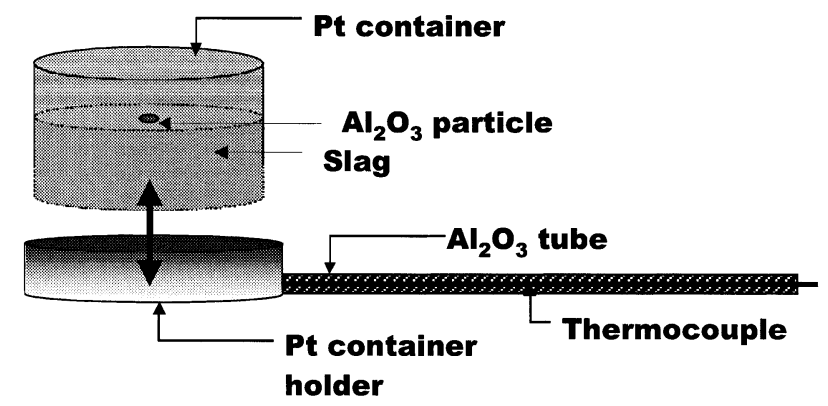

Fig. 2. Schematic of the Sample Set-up of the CLSM.

Table 1. Slag sample composition.

\begin{tabular}{|l|l|l|l|l|l|l|}
\hline Sample & $\mathrm{wt} \% \mathrm{CaO}$ & $\mathrm{wt} \% \mathrm{SiO}_{2}$ & $\mathrm{wt} \% \mathrm{Al}_{2} \mathrm{O}_{3}$ & $\mathrm{wt} \% \mathrm{MgO}$ & $\mathrm{T}_{\mathrm{L}}$ & $\mathrm{T}_{\mathrm{EUr}}$ \\
\hline 1 & 33.4 & 39.5 & 19.5 & 7.3 & $1330^{\circ} \mathrm{C}^{20)}$ & $1290^{\circ} \mathrm{C}^{20)}$ \\
\hline 2 & 35.7 & 42.51 & 21.2 & 0.4 & $1303^{\circ} \mathrm{C}^{21)}$ & $1264^{\circ} \mathrm{C}^{20)}$ \\
\hline 3 & 39.9 & 40.12 & 20.4 & & $1290^{\circ} \mathrm{C}^{21)}$ & $1264^{\circ} \mathrm{C}^{21)}$ \\
\hline
\end{tabular}

The slag Samples were heated at a heating rate of $15^{\circ} \mathrm{C} / \mathrm{s}$ under a high purity argon atmosphere $\left(P_{\mathrm{O}_{2}}=10^{-5} \mathrm{~atm}\right)$ to a $1420^{\circ} \mathrm{C}$ and subsequently cooled to the experimental temperature at a cooling rate of $5^{\circ} \mathrm{C} / \mathrm{s}$. The experimental temperatures were between $1350-1050^{\circ} \mathrm{C}$.

\section{Phase and Elemental Analysis}

Scanning Electron Microscope (SEM) was used to study the microstructure of crystals in Samples that were quenched during crystal growth. The SEM is equipped with an Energy Dispersion X-ray Spectroscopy (EDX or EDS) unit that allows compositional measurements to be done. In this study the EDX was used for linescans where a number of measurements are performed along a straight line on the Sample surface with an equal distance between the points of measurements. Elementary mapping was also performed with EDX unit to better clarify segregation of elements that occurs as a result of crystallization. The identification of the precipitated crystalline phases was performed by powder X-ray diffraction. The Samples for the SEM study and the X-ray diffraction were prepared by using the Double Hot Thermocouple Technique (DHTT) which allows the Sample to be quenched at a cooling rate of $300^{\circ} \mathrm{C} / \mathrm{s}$. The DHTT has been described in detail elsewhere. ${ }^{18)}$

\section{Results and Discussion}

The crystallization behavior of slags, where alumina particles were added as heterogeneous nucleation sites, was studied for three different slag Samples with compositions shown in Table 1. The liquidus temperature $\left(T_{\mathrm{L}}\right)$ and the eutectic temperature $\left(T_{\mathrm{EUT}}\right)$ were determined from the phase diagrams for the present slag systems. ${ }^{19,20)}$ It is well known from classical nucleation theory that the onset of crystallization in slags must be a function of cooling rate. To determine the transformation kinetics of crystallization behavior in an undercooled slag one must construct either time temperature transformation (TTT) or continuous cooling transformation (CCT) curves. Figure 3 shows a TTT diagram obtained by the DHTT for the onset crystallization for Sample 1. The obtained TTT curve forms a classic Cshape as predicted by classical crystal growth and nucle- 
ation theory with the nose position at $1100^{\circ} \mathrm{C}$ with a minimum incubation time of $60 \mathrm{sec}$.

\subsection{Effect of Alumina as Heterogeneous Nuclei}

In all experiments performed with the CLSM, the melt remained as an undercooled liquid during cooling to the experimental temperature. The crystals precipitating on the alumina particles close to the liquidus temperature exhibited a cubic morphology and grew as blocks on the alumina particle. Experimental images from Sample 1 at $1330^{\circ} \mathrm{C}$ are shown in sequence for crystallization of these cubic crystals in Fig. 4. The growth of these cubic crystals was limited and stopped after the particle size reached $100 \mu \mathrm{m}$ in width and height. In the case of Sample 1 the introduction of alumina particles increased the temperature range of crystallization by $150^{\circ} \mathrm{C}$ compared to crystallization experiments without any alumina particles present in the melt. In

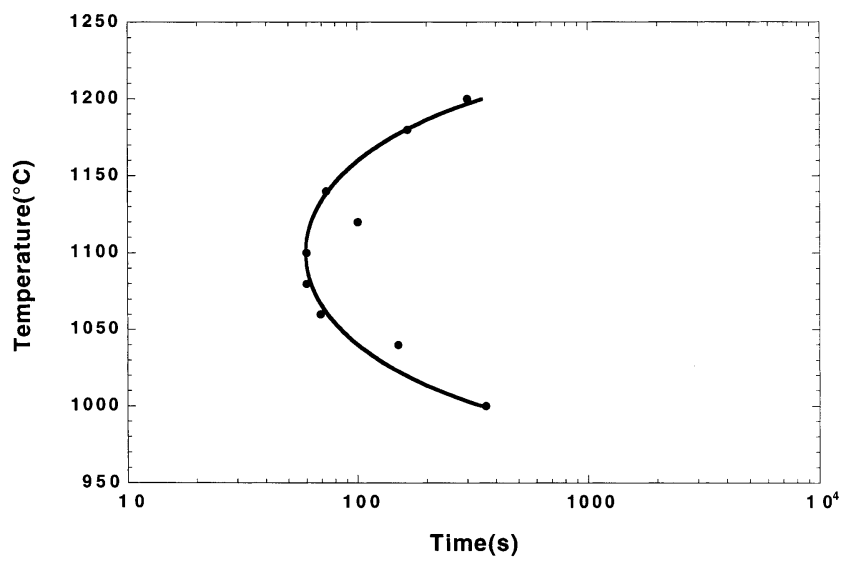

Fig. 3. TTT diagram for the onset of crystallization of Sample 1. addition to increased temperature range the onset of crystallization was almost instantaneous when the Samples reached the experimental temperature. Thus, the introduction of the alumina particle in the melt eliminated the potential to under cool the Sample.

Some of the cubic crystals detached from the alumina particle and were transported out in the melt as single crystals by convection. An example of a single cubic crystal at $1330^{\circ} \mathrm{C}$ is shown in Fig. 5.

The crystal in Fig. 5 is fully transparent as the bottom of the platinum pan can be observed through the crystal. Only by the shadows of the edges can the crystal be detected. The size of the crystal in Fig. 5 was measured with time as it detached from the particle and moved out in the melt. The result is shown in Fig. 6.

The size of this crystal at $1330^{\circ} \mathrm{C}$ is more or less constant during the measured time period. As the crystal in Fig. 5 is not changing size, it is reasonable to assume that the crystal is in equilibrium with the melt. Since these blocky crystals appear at temperatures at and even above the liquidus temperature it suggests that they are not the stable phases predicted by phase diagram..$^{20,21)}$ The phase is formed due to slow dissolution kinetics and reaction between the surface of the alumina particle and the slag. Samples 2 and 3 exhibited, in the temperature region close to the liquidus temperature, limited precipitation of blocky crystals similar to that found in Sample 1.

\subsection{Crystal Growth below the Thermodynamic Eu- tectic Temperature}

As the experimental temperature decreased, the crystal morphology changed from blocky to dendritic crystals for Sample 1 and 3. For Sample 2 needle shaped crystals were

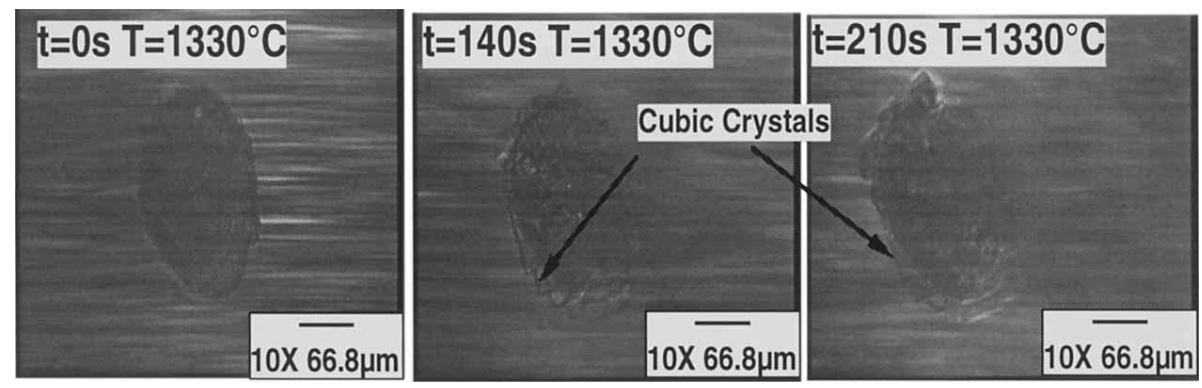

Fig. 4. Experimental images of cubic crystal growth at $1330^{\circ} \mathrm{C}$ on alumina particle for Sample 1 .

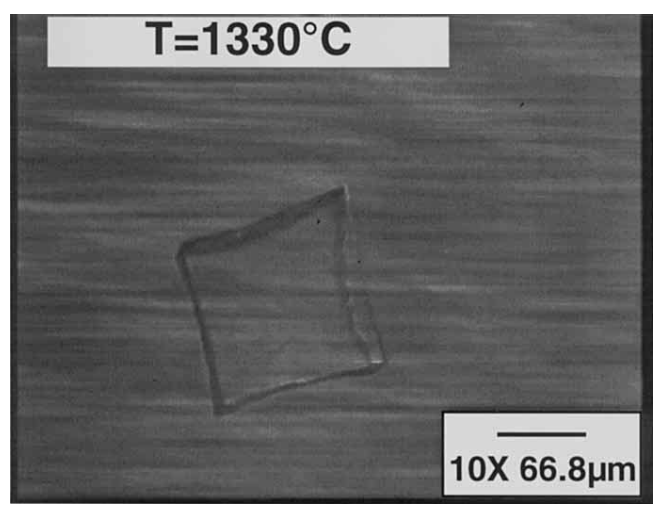

Fig. 5. Single detached cubic crystal in the melt at $1330^{\circ} \mathrm{C}$ for Sample 1.

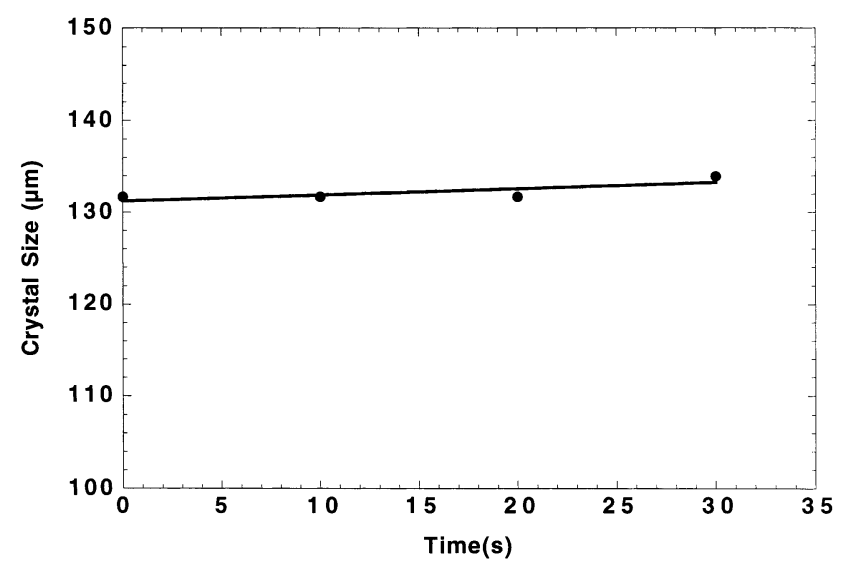

Fig. 6. Measured growth of cubic crystal at $1330^{\circ} \mathrm{C}$. 

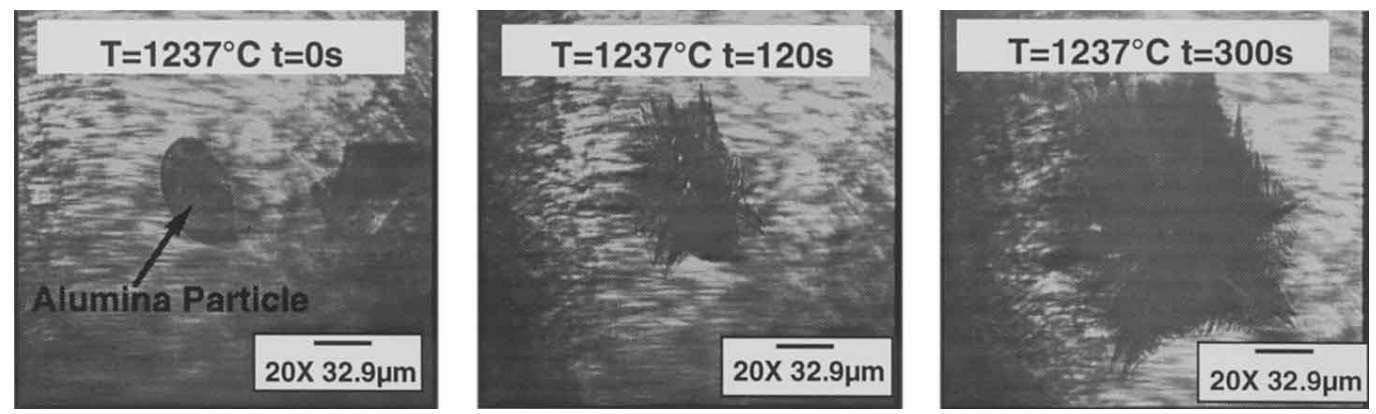

Fig. 7. Experimental images of dendritic crystals growing out from an $\mathrm{Al}_{2} \mathrm{O}_{3}$ particle at $1237^{\circ} \mathrm{C}$ in Sample 1.

Table 2. Crystal morphologies precipitating at different temperatures.

\begin{tabular}{|l|l|l|l|}
\hline Morphology & Sample 1 & Sample 2 & Sample 3 \\
\hline Blocky & $1350^{\circ} \mathrm{C}<\mathrm{T}<1275^{\circ} \mathrm{C}$ & $1300^{\circ} \mathrm{C}<\mathrm{T}<1250^{\circ} \mathrm{C}$ & $1300^{\circ} \mathrm{C}<\mathrm{T}<1250^{\circ} \mathrm{C}$ \\
\hline Needle shaped & & $1250^{\circ} \mathrm{C}<\mathrm{T}<1100^{\circ} \mathrm{C}$ & \\
\hline Dendrites & $1275^{\circ} \mathrm{C}<\mathrm{T}<1050^{\circ} \mathrm{C}$ & $1100^{\circ} \mathrm{C}<\mathrm{T}<1050^{\circ} \mathrm{C}$ & $1250^{\circ} \mathrm{C}<\mathrm{T}<1050^{\circ} \mathrm{C}$ \\
\hline
\end{tabular}

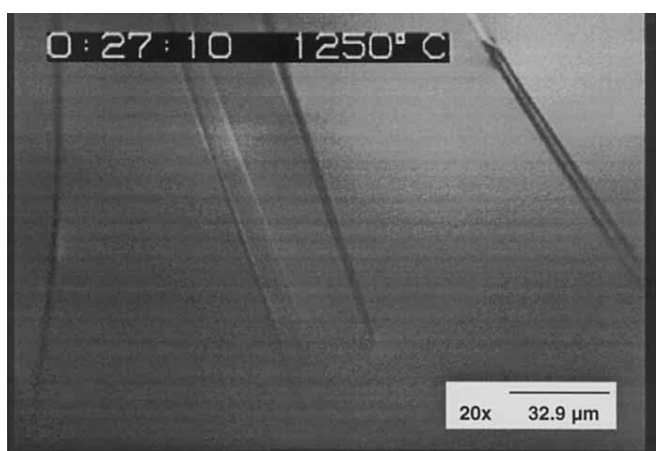

Fig. 8. Needle shaped crystals growing at $1250^{\circ} \mathrm{C}$ in Sample 2 .

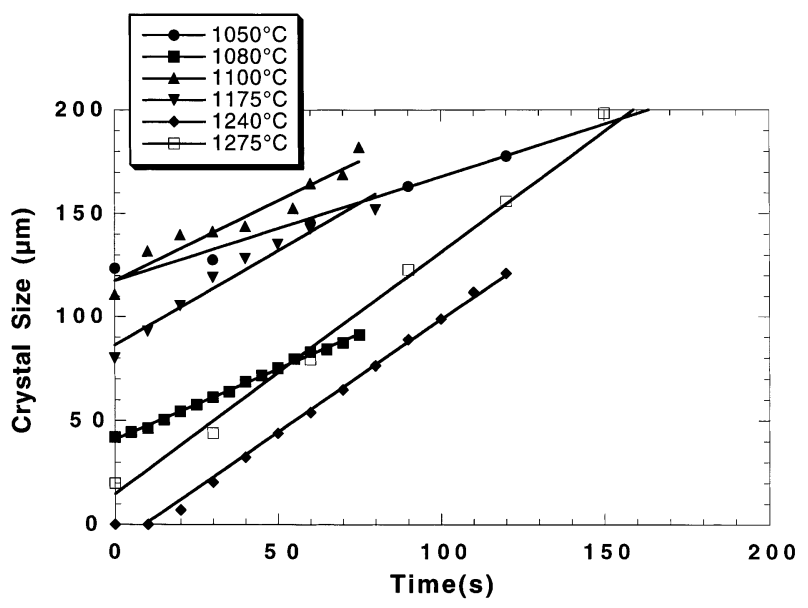

Fig. 9. Measured crystal growth for Sample 1 at different temperatures.

observed between $1250^{\circ} \mathrm{C}$ and $1100^{\circ} \mathrm{C}$ and dendritic crystals below $1100^{\circ} \mathrm{C}$. At temperatures below $T_{\text {EUT }}$ the crystal growth rate become continuous and was only interrupted when crystal arms grew together or reached the walls of the Sample holder. The observed crystal morphologies with temperature are summarized in Table 2.

The growth of dendritic crystals nucleated on an alumina particle as a function of time at $1237^{\circ} \mathrm{C}$ is shown in Fig. 7.

The dendritic structure is easily recognized with the formation of both secondary and tertiary arms. Figure 8

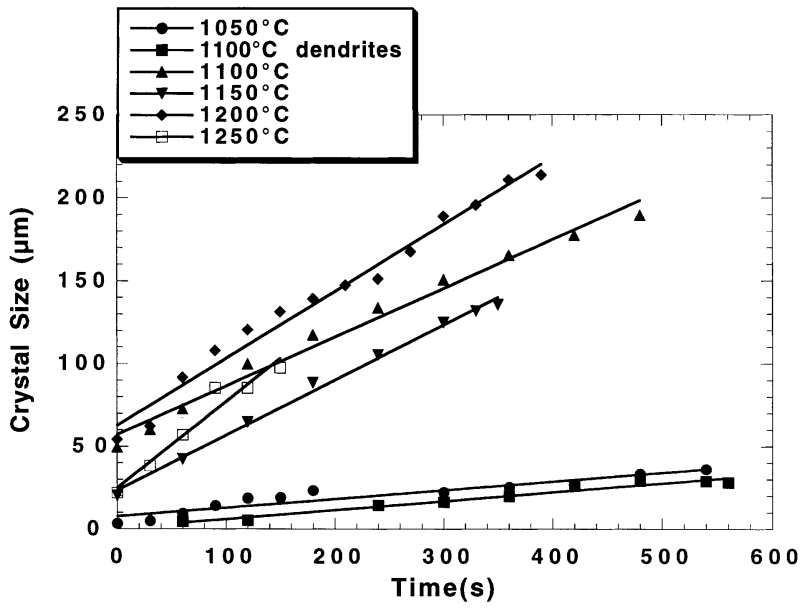

Fig. 10. Measured crystal growth for Sample 2 at different temperatures.

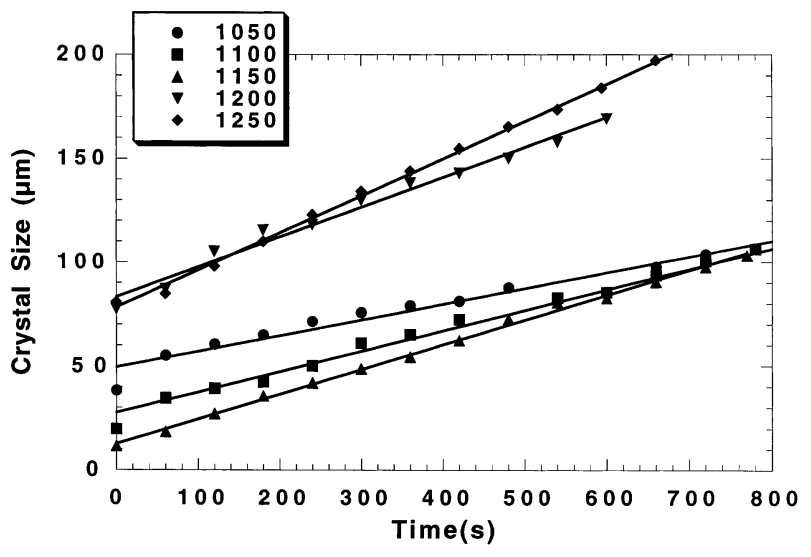

Fig. 11. Measured crystal growth for Sample 3 at different temperatures.

shows needle shaped crystals at $1250^{\circ} \mathrm{C}$ for Sample 2 .

Crystal growth was measured by using a computer image analysis program (NIH 1.62) and the crystal growth as a function of time is shown in Figs. 9, 10 and 11 for Sample 1,2 and 3 respectively.

The temperature dependence of the growth rate for the different Samples is shown in Figs. 12-14.

For Sample 1 and 3 the growth rate shows linear temperature dependence although the crystal growth rate for Sample 1 is almost ten times that of Sample 3. The growth rate for Sample 2 shows a more complicated temperature dependence, the growth rate decreases non linearly for the needle shaped crystals and then drops significantly as the 


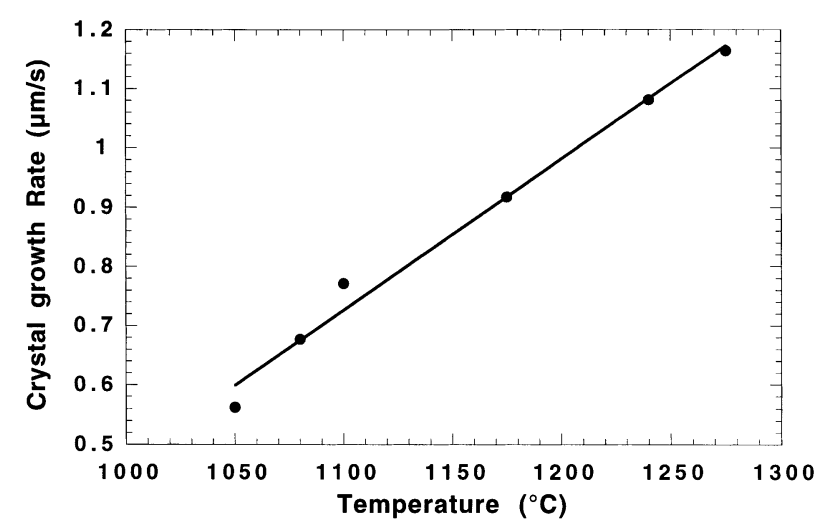

Fig. 12. Growth rate versus temperature for Sample 1.

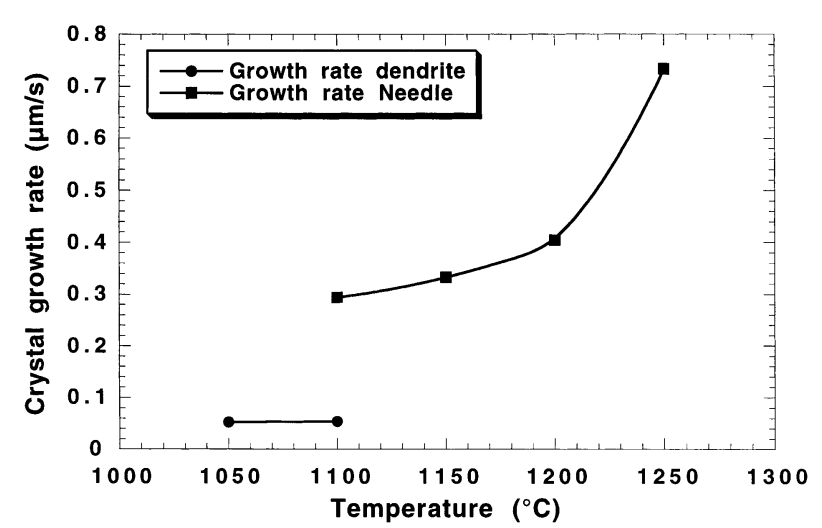

Fig. 13. Growth rate versus temperature for Sample 2.

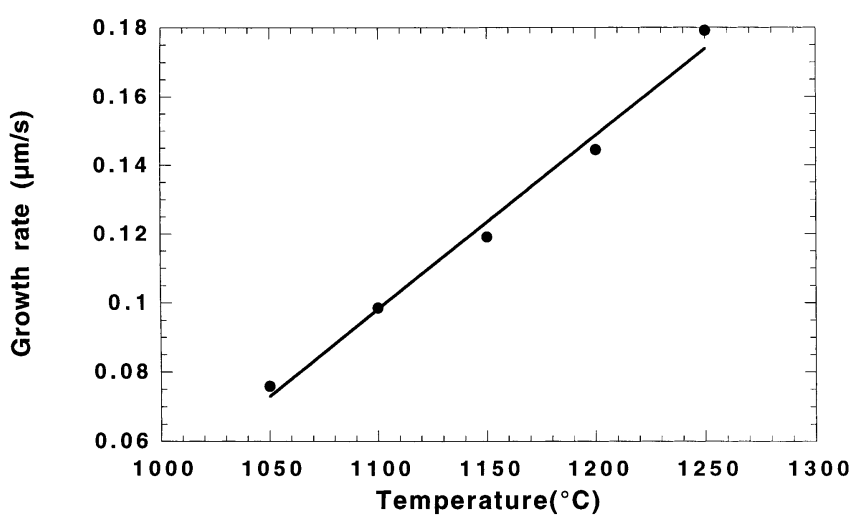

Fig. 14. Growth rate versus temperature for Sample 3.

crystal morphology transforms to dendritic crystals with decreasing temperature.

The crystal growth rate was found to be linear at a fixed temperature. Therefore, it can be assumed that the growth rate is controlled by a steady state rate of mass transfer through a diffusion layer near the crystal/melt interface. By studying the phase diagrams shown in Fig. 15 for the present slag systems the following can be concluded:

- The first phase to precipitate for Sample 1 is Melilite (4CaO-MgO- $3 \mathrm{SiO}_{2}-\mathrm{Al}_{2} \mathrm{O}_{3}$ ) and as the melt temperature decreases a ternary eutectic is reached at $1290^{\circ} \mathrm{C}$ involving Melilite, Spinel and Anorthite.

- In the case of Sample 2 and 3 the first phase to precipitate is Anorthite and Gehelenite respectively and as the melts reach $1264^{\circ} \mathrm{C}$ there is a ternary eutectic with Anorthite, Gehlenite and Wollastonite. (a)

(b)
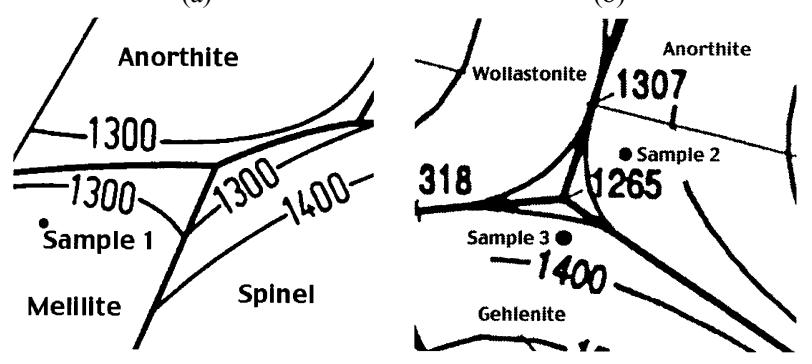

Fig. 15. Part of phase diagrams showing the position of Sample compositions and the eutectics. ${ }^{11)}$

Table 3. Composition of the present crystalline phases.

\begin{tabular}{|l|l|l|l|l|}
\hline Crystalline phase & $\mathrm{wt} \% \mathrm{CaO}$ & $\mathrm{wt} \% \mathrm{SiO}_{2}$ & $\mathrm{wt} \% \mathrm{Al}_{2} \mathrm{O}_{3}$ & $\mathrm{wt} \% \mathrm{MgO}$ \\
\hline Melilite & 41.02 & 32.97 & 18.64 & 7.37 \\
\hline Anorthite & 20.16 & 43.19 & 36.65 & \\
\hline Gehlenite & 40.90 & 21.91 & 37.18 & \\
\hline
\end{tabular}

It is likely that a primary phase is precipitated first and at very long holding times the equilibrium structure is formed. X-ray diffraction was performed on Samples quenched from $1150^{\circ} \mathrm{C}$ and the crystalline phases were identified. For Sample 1 the crystalline phase was identified as Melilite, for Sample 2 it was Anorthite and for Sample 3 it was Gehlenite. The results from the X-ray diffraction shows that at $1150^{\circ} \mathrm{C}$, the primary phase to precipitate in the undercooled liquid is the same as predicted by the phase diagram from the liquidus surface. The crystallization occurs in these experiments only from a few alumina particles acting as sites for heterogeneous nucleation. The crystalline fraction was less than $20 \%$ during the measurement of the growth rate so the bulk melt composition ahead of the crystals is most likely unaffected at the time of growth measurement. A metastable concentration gradient is therefore assumed between the dendrite tip and the bulk melt by just considering the concentration difference between the crystalline phase and the original melt composition. The composition of the crystalline phases that were found is summarized in Table 3.

By comparing the original melt composition from Table 1 with the crystalline compositions in Table 3 it can be concluded that:

- For Sample 1 the major composition difference between the bulk liquid and the crystalline phase, Melilite is in the content of $\mathrm{CaO}$ and to less extent in the contents of $\mathrm{SiO}_{2}$ and $\mathrm{Al}_{2} \mathrm{O}_{3}$.

- Anorthite that was found to precipitate in Sample 2 has an approximately half the content of $\mathrm{CaO}$ compared to the original melt of. The $\mathrm{Al}_{2} \mathrm{O}_{3}$ content is about $15 \%$ higher in the crystalline phase.

- The original composition of Sample 3 contains approximately double the $\mathrm{SiO}_{2}$ content and $17 \%$ less $\mathrm{Al}_{2} \mathrm{O}_{3}$ compared to Gehlenite.

To find a reasonable value for the effective boundary layer thickness at the interface a SEM (Scanning Electron Microscope) specimens were prepared for a detailed study of the crystal liquid interface. Figure 16 shows a SEM image revealing the detail of the crystal interface between crystals and the surrounding melt. The dendrite tip found in Sample 1 shows the primary dendrite and the formation of 
(a)

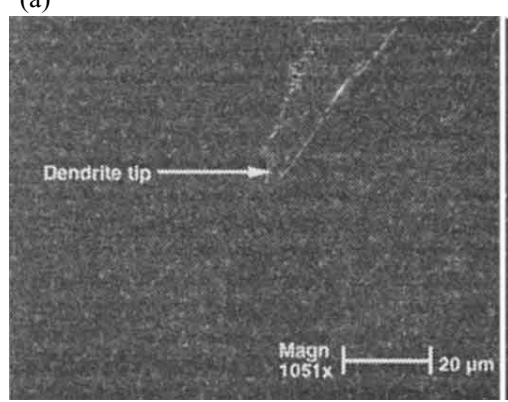

(b)

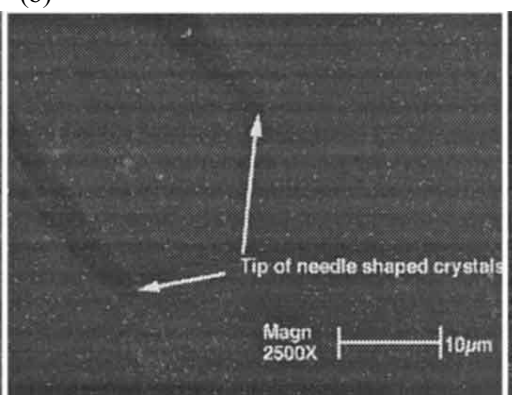

(c)

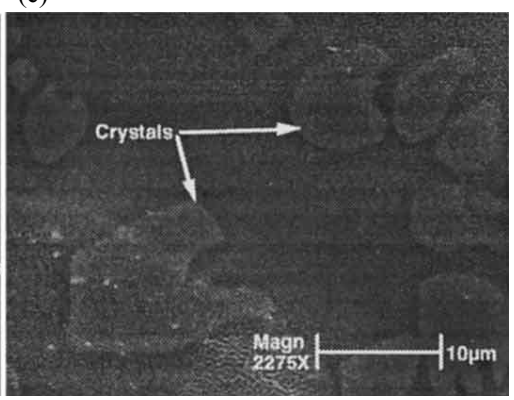

Fig. 16. SEM image of crystal/melt interface for (a) Sample 1, and (b) Sample 2 and (c) Sample 3.

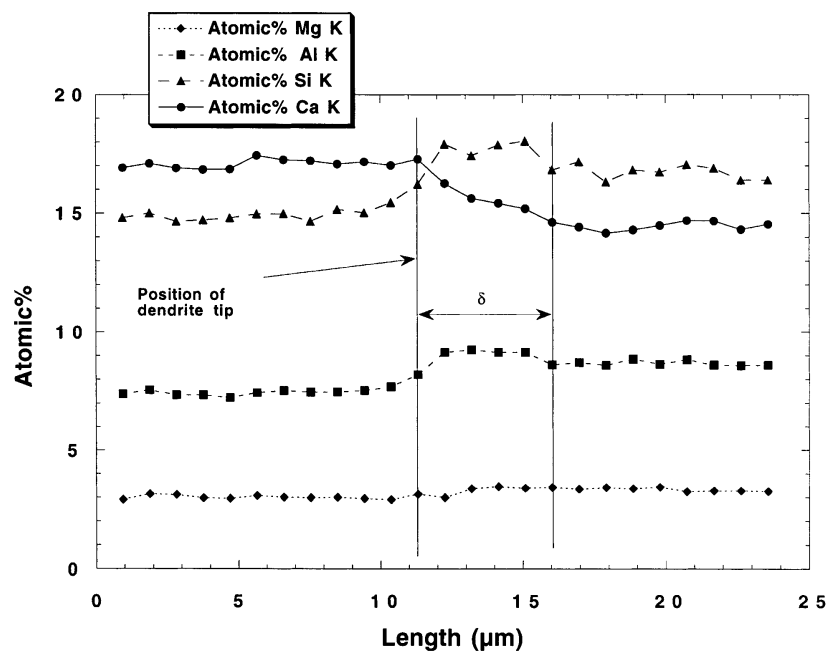

Fig. 17. Compositions along the dendrite in Fig. 15(a) out in the melt for Sample 1. The markers represent points of measurement.

secondary dendrites along the dendrite arm in Fig. 16(a). The needle shaped crystals observed in Sample 2 is easily recognized in Fig. 16(b) and there is no indication of formation of secondary arms on the crystals. The crystals in Fig. 16(c) are probably part of a dendrite arm where the primary dendrite was lost in the polishing process.

Linescans of the composition along the crystals out in the melt were performed to determine a value for the diffusion boundary layer. The result from the linescans is displayed in Figs. 17-19. For Sample 2 and 3, oxygen was excluded from the linescan to better clarify the changes in composition of $\mathrm{Al}$, and $\mathrm{Ca}$ and $\mathrm{Si}$.

The concentration of $\mathrm{Ca}$ is decreasing moving from the dendrite in Sample 1 out in the melt while the concentration of $\mathrm{Al}$ and $\mathrm{Si}$ is increasing from the tip out in the melt due to the reaction of solute. In the case of Sample 2 where Anorthite was present the $\mathrm{Si}$ content is almost constant along the scan while the Ca concentration increases in the melt and the Al content is higher in the crystals. For Sample 3 the Si concentration is lower in the crystal while the content of alumina is significantly higher and the $\mathrm{Ca}$ concentration is constant along the measured line. The length of $\delta$ is determined from Figs. 17-19 to be 6.0, and 3.3 and $2.1 \mu \mathrm{m}$ for Sample 1, and Sample 2 and Sample 3 respectively. As slags can be considered to be ionic melts it is naturally not elementary $\mathrm{Al}$ or $\mathrm{Si}$ that is rejected but rather some ions or ionic complex like $\mathrm{Ca}^{2+}, \mathrm{O}^{2-}, \mathrm{AlO}_{3}{ }^{3-}$, and $\mathrm{SiO}_{4}{ }^{4-}$ and so forth. To further support the assumption

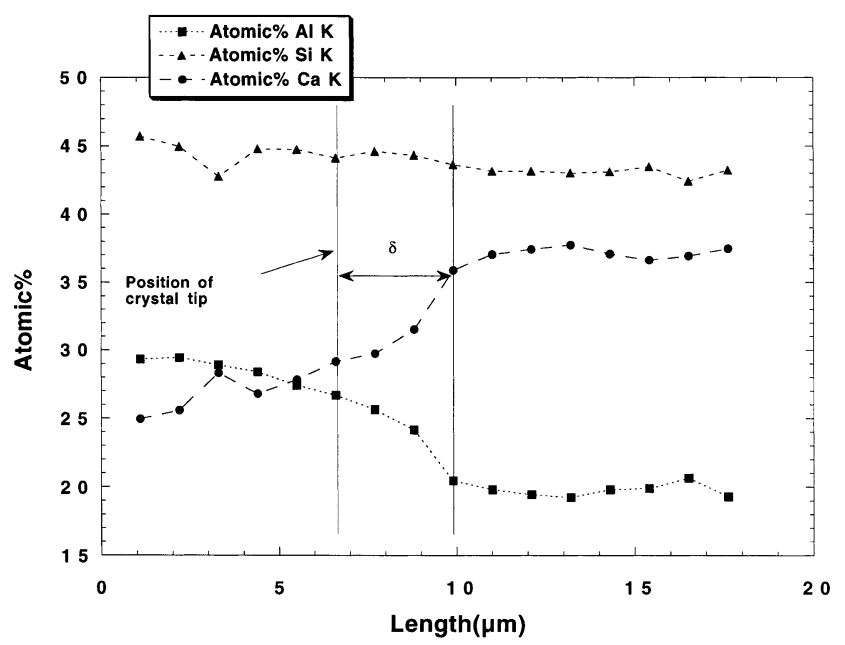

Fig. 18. Composition along needle shaped crystal in Fig. 15(b) out in the melt for Sample 2. The markers represent points of measurement.

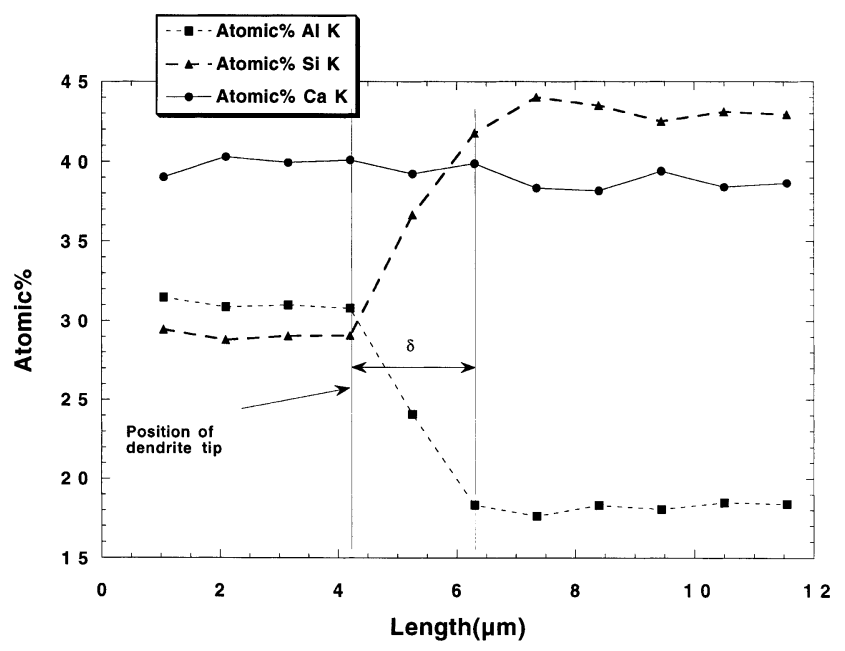

Fig. 19. Compositions along crystal in Fig. 16(c) out in the melt for Sample 3. The markers represent points of measurement.

that an estimation of the concentration gradient can be assumed by only considering the composition of the melt and the crystal and to better clarify the rejection of solute during crystallization elemental mapping was performed over a region containing both crystals and the quenched melt. The regions subjected to elemental mapping and the results from the mapping are shown in Figs. 19-21. The images in Figs. 20-22 have been digitally enhanced to increase the 


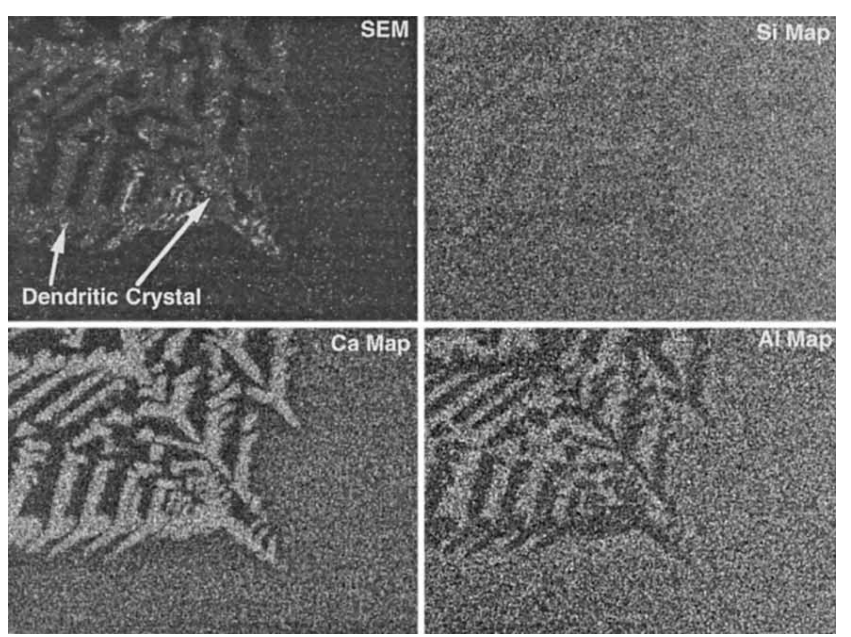

Fig. 20. Elementary mapping of region containing both crystals and melt for Sample 1.
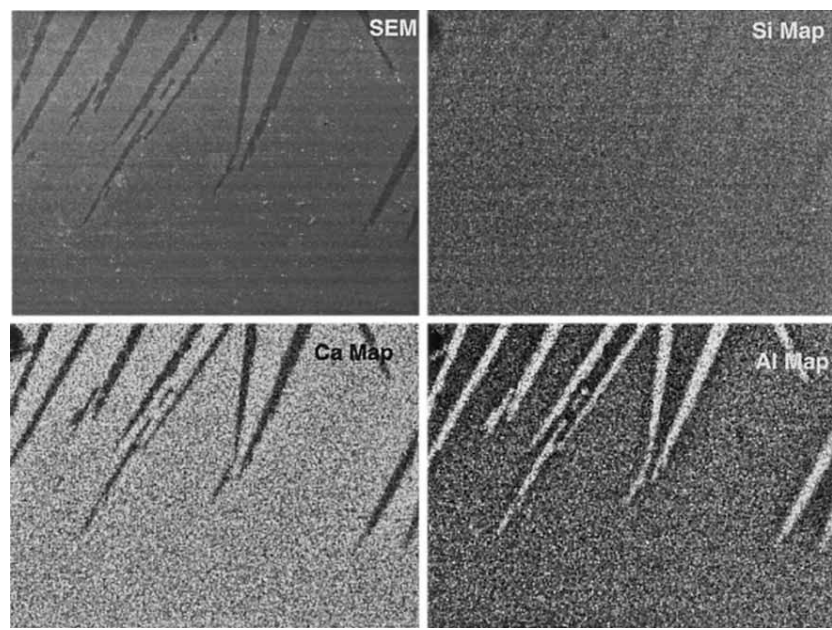

Fig. 21. Elementary mapping of region containing both crystals and melt for Sample 2 .
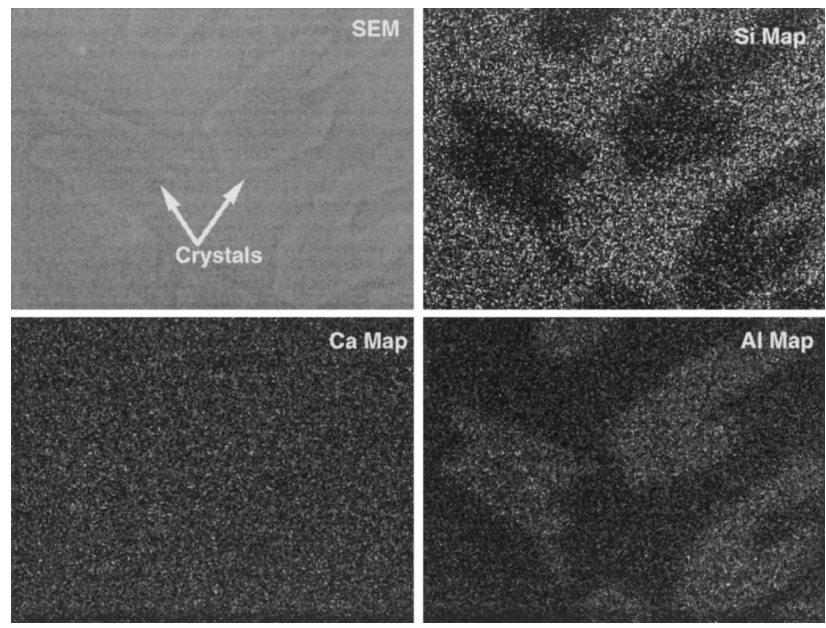

Fig. 22. Elementary mapping of region containing both crystals and melt for Sample 3.

contrast. The segregation of $\mathrm{Ca}$ and $\mathrm{Al}$ appears clearly while the difference in $\mathrm{Si}$ content is hard to define for Sample 1. For the $\mathrm{Mg}$ in Sample 1 no segregation was found. The crystalline region clearly consists of higher concentration of $\mathrm{Ca}$ while the interdendritic liquid shows a higher concentration of $\mathrm{Al}$ that was rejected during crystal-
Table 4. Comparison between the measured and calculated growth rate using Eq. (1) at $1150^{\circ} \mathrm{C}$.

\begin{tabular}{|l|l|l|}
\hline Sample & Measured Growth Rate $(\mu \mathrm{m} / \mathrm{s})$ & Calculated Growth Rate $(\mu \mathrm{m} / \mathrm{s})$ \\
\hline 1 & 0.85 & 0.032 \\
\hline 2 & 0.33 & 0.076 \\
\hline 3 & 0.12 & 0.21 \\
\hline
\end{tabular}

lization.

The segregation of $\mathrm{Al}$ and $\mathrm{Ca}$ is clear for Sample 2 and it can be seen that $\mathrm{Ca}$ is rejected during crystallization. For Sample 3 the $\mathrm{Si}$ is being rejected during the formation of Gehlenite and it is also easy to recognize the segregation of Al. It is obvious that the crystallization of slags shows resemblance to the solidification behavior of metallic alloys although the crystals have a stoichiometric composition along its total length.

Christensen et al. ${ }^{22)}$ suggested the following simple model relating the growth rate to the concentration gradient at the interface:

$$
u=\frac{D\left(C_{0}-C_{\mathrm{E}}\right)}{\delta\left(1-C_{\mathrm{E}}\right)}
$$

$u=$ growth rate

$D=$ diffusion coefficient

$\delta=$ effective boundary layer thickness at the interface

$C_{0}=$ composition of original melt

$C_{\mathrm{E}}=$ equilibrium composition at the interface

This model does not consider the shape of the crystals when evaluating the growth rate but just diffusion across a boundary layer driven by a concentration gradient. In order to use Eq. (1) the diffusion coefficient and the concentration gradient has to be established.

The diffusion coefficient can be estimated with the Eyring equation: ${ }^{23)}$

$$
D=\frac{k T}{\eta \lambda}
$$

$$
\begin{aligned}
& k=\text { Boltzmann constant } \\
& \eta=\text { viscosity } \\
& \lambda=\text { mean interatomic difference }(2 r)
\end{aligned}
$$

The viscosity data was obtained by using the viscosity model developed at the Department of Metallurgy, Royal Institute of Technology, Stockholm, Sweden. ${ }^{24)} \mathrm{SiO}_{2}$ was assumed to diffuse as $\mathrm{SiO}_{4}{ }^{4-}$ and, $\mathrm{CaO}$ as $\mathrm{Ca}^{2+}$ and $\mathrm{Al}_{2} \mathrm{O}_{3}$ as $\mathrm{AlO}_{3}{ }^{3-}$ for the estimation of radius of the diffusing species. The data for ionic radius was taken from Shannon et al. ${ }^{25,26)}$ For Sample 1 and 3 it is assumed that diffusion of ionic silica complex is rate controlling and for Sample 2 the diffusion of alumina ions is rate controlling. This assumption was base on that the biggest complexes would have the lowest mobility and thereby be rate controlling.

The comparison between the measured and the calculated growth rate at $1150^{\circ} \mathrm{C}$ can be seen in Table 4 where it can be seen that the growth rate cannot be explained by Eq. (1).

It is well known in solidification theory that there is relationship between the radius of the primary arm of a dendrite and the growth rate of the dendrite. A dendrite tip can be described as paraboloid of revulotion and Ivantsov ${ }^{27)}$ de- 


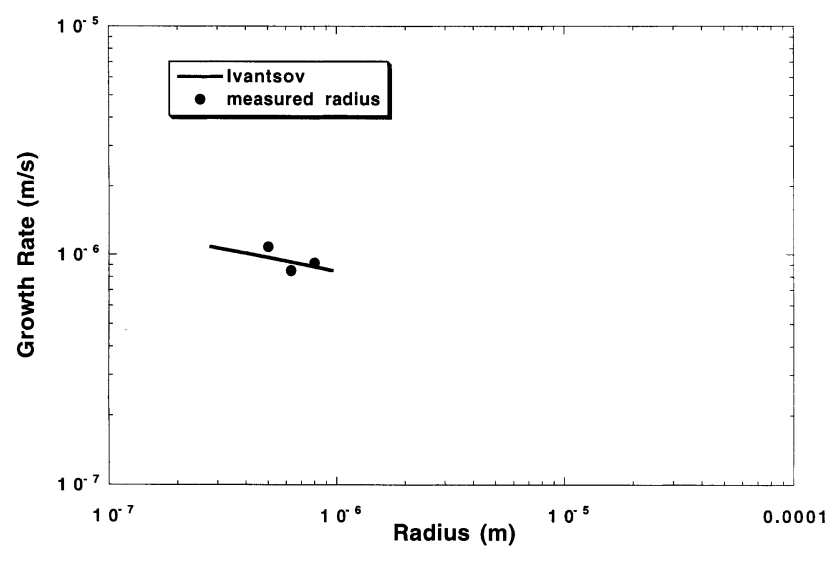

Fig. 23. Measured and calculated tip radius for Sample 1.

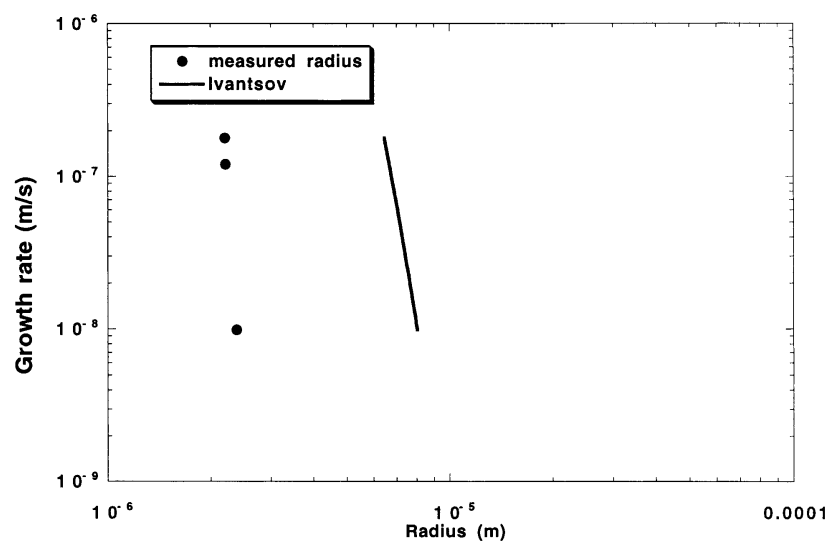

Fig. 24. Measured and calculated tip radius for Sample 3.

veloped a mathematical analysis for the diffusion problem of paraboloid. The following relationship between dimensionless supersaturation $\Omega$, and dendrite tip radius and growth rate was obtained:

$$
\Omega=I\left(P_{\mathrm{C}}\right)
$$

$P_{\mathrm{C}}$ is the solute $\mathrm{P}$ 'eclet number.

$$
\begin{gathered}
\Omega=\frac{C_{1}^{*}-C_{0}}{C_{1}^{*}(1-k)} \\
k=\frac{C_{\mathrm{s}}^{*}}{C_{1}{ }^{*}} \ldots \ldots
\end{gathered}
$$

$C_{1}^{*}=$ concentration at the liquid interface

$C_{\mathrm{s}}{ }^{*}=$ concentration at the solid interface

$$
I\left(P_{\mathrm{C}}\right)=P_{\mathrm{C}} \exp E 1\left(P_{\mathrm{C}}\right)
$$

Equation (6) can be approximated as continued fraction and if only the two first terms is considered the following expression is obtained:

$$
\begin{gathered}
I\left(P_{\mathrm{C}}\right) \approx P_{\mathrm{C}}+\frac{P_{\mathrm{C}}}{P_{\mathrm{C}}+1} \\
P_{\mathrm{C}}=\frac{u R}{2 D} \ldots \ldots . .
\end{gathered}
$$

$R=$ dendrite tip radius

The experimental images from the CLSM were reviewed for dendrite tip radius measurements and in three cases for Sample 1 and Sample 3, could the dendrite tip radius be satisfactorily measured. For Sample 2 problems with resolution and contrast between crystal tip and melt did not allow precise measurement of the radius at higher magnifications. The values for the concentration at the liquid interface were obtained by extrapolating the liquidus curves in the phase diagram. The concentration at the solid interface was assumed to equal the crystal composition and again the diffusion of $\mathrm{SiO}_{2}$ ions was considered. The comparison of the measured data and the calculated values by using Ivantsov solution for Sample 1 and Sample 3 is shown in Figs. 23 and 24.

The fit between the calculated values and the measured is very good for Sample 1. For Sample 3 is the calculated radius approximately thrice the size of the measured radii. However, considering that the diffusion data was estimated from viscosity calculations and that the liquidus lines were extrapolated from the ternary phase diagram this result is still good. It is clear that for a correct description of the dendritic growth in slags the tip radius must be known.

It is clear from this work that the presence of alumina particles in these slag melts caused precipitation to occur near the liquidus temperature of the slags. Thus, alumina is a potent nucleating agent in these systems. In steelmaking, this means that the presence of alumina particles in liquid slags that are cooling will lead to slag crystallization at higher temperatures and shorter times than would be observed under other conditions.

\section{Conclusions}

By the means of the CLSM slag crystallization in synthetic slags in the presence of alumina particles was observed in situ. Alumina particles act as heterogeneous nucleation sites for precipitation of the primary equilibrium phases as predicted by the phase diagram and practically eliminate undercooling in these slag systems. The growth rate of the crystals was found to fit well with predictions using Ivantsov's solution of the diffusion equation around a parabaloid of revolution.

\section{Acknowledgments}

The authors would like to thank the member companies of the Center for Iron and Steelmaking Research for their financial support. A special thanks goes to Prof. Seetharaman's group at the Department of Metallurgy at Royal Institute of Technology, Stockholm, Sweden for providing the means to calculate the viscosity data and to $\mathrm{N}$. Biery and T. Nuhfer at CMU for aid in SEM techniques.

\section{REFERENCE}

1) S. Sridhars and A. W. Cramb: Metall. Mater. Trans. B, 31B (2000), No. 2, 406 .

2) C. Tse, S. H. Lee, S. Sridhar and A. W. Cramb: Proc of the 83rd Steelmakings Conf., ISS, Warrendale, PA, (2000).

3) C. Gatellier, H. Gaye, J. Lehmann, J. N. Pontoire and P. V. Riboud: Steel Res., 64, (1993), 87.

4) P. Rocabois, J. N. Pontoire, H. Gaye, J. Lehmann and C. Gatellier: Rev. Metall., 94 (1997), No. 11, 1393.

5) C. Orrling, A. Tilliander, Y. Kashiwaya and A. W. Cramb: Trans. Iron Steel Soc., 27 (2000), No. 1.

6) C. Orrling and A. W. Cramb: Metall. Mater. Trans. B, 31B (2000), 
No. 2, 403 .

7) P. J. Vergano and D. R. Uhlmann: J. Non-Cryst. Solids, 48 (1982), 393.

8) P. J. Vergano and D. R. Uhlmann: Phys. Chem. Glasses, 11 (1970), 39.

9) I Avramov, R. Pascova, B. Samouneva and I. Gutzow: Phys. Chem. Glasses, 20 (1979), 91.

10) L. C. Klein and D. R. Uhlmann: J. Geophys. Res, 79 (1974), 486.

11) A. C. Havermans, N. H. Stein and J. M. Stevens: J. Non-Cryst. Solids, 5 (1970), 66.

12) E. Asayama, H. Takebe and K. Morinaga: ISIJ Int., 33 (1993), 233.

13) M. Ohta, H. Kohzuka and N. Soga: Yogokaishi, 92 (1984), 464.

14) C. Y. Fang, H. Yinnon and D. R. Uhlmann: J. Non-Cryst. Solids, 57 (1983), 465.

15) K. Tsutsumi, T. Nagasaka and M. Hino: Tetsu-to-Hagané, 84 (1998), 464.

16) H. Shibata and T. Emi: Materia Jpn., 36 (1997), No. 8, 809.

17) H. Chikama, H. Shibata, T. Emi and M. Suzuki: Mater. Trans. JIM,
37 (1996), No. 4, 620.

18) C. Orrling, Y. Fang, N. Phinichka, S. Sridhar and A. W. Cramb: Observation and Measurement of Solidification Phenomena at High Temperatures, JOM-e, July (1999), http://www.tms.org/pubs/journals/JOM/9907/Orrling/Orrling-9907.html.

19) Y. Kashiwaya, C. Cicutti, A. W. Cramb and K. Ishii: ISIJ Int., 38, (1998), No. 4, 348.

20) Slag Atlas; 5th ed., Verlag Stahleisen, Düsseldorf, (1995), 158.

21) G. Eriksson and A. D. Pelton: Metall. Trans. B, 24B (1993), 807.

22) N. H. Christensen, A. R. Copper and B. S Rawal: J. Am. Ceram. Soc., 56 (1973), 557.

23) Slag Atlas; 5th ed., Verlag Stahleisen, Düsseldorf, (1995), 545.

24) S. Seetharaman, Du Sichen and J. Y. Zhang: JOM, 51 (1999), No. 8, $38-40$.

25) R. D. Shannon: Acta Cryst., B25 (1969), 925.

26) R. D. Shannon: Acta Cryst., A32 (1976), 751.

27) G. P. Ivantsov: Dokl. Akad. Nauk SSSR, 58, (1947), 567. 